\title{
Specificity of communication teacher-student in informational and technological era
}

\author{
Valentin V. Mironov ${ }^{1, *}$ \\ ${ }^{1}$ Ryazan State Radio Engineering University, 390005, Ryazan, Russia
}

\begin{abstract}
Some of the fundamental problems, relating to the learning process in the system "teacherstudent" in the information, technological era, are discussed in this article.
\end{abstract}

\section{Introduction}

In recent years in connection with universal development and introduction of information technologies persistent attempts to introduce these technologies and in such thin "matter" as process of communication of the teacher and his pupil are carried out to economic, social, political, scientific, education spheres of action of the person. The problem, in our opinion, consists that society wants to limit or accompany with these new, computer technologies all process of training which, no doubt, is inseparable from pedagogics. Whether there is no serious mistake here (so inherent in the Russian consciousness which is safely rushing from one "outdated" to other "new")?

Let's answer this rhetorical question and we will consider a problem in more detail (keeping within the taken-away format!). Really, pedagogics [greek: paidagogike] is a science about education and training of the person; technology [greek: techne - art, skill; and $\log o s$ - the word] - it is 1) set of methods of processing, production, change of a state, properties, forms of raw materials, materials in the course of production; 2) science about ways of impact on raw materials, materials, semi-finished products, the corresponding instruments of production; innovation - the new phenomenon [1].

Considering the pupil of the higher school as unity of future professional and personality, right there we fall into a contradiction in questions of applicability of pedagogical and information technologies. Really, we will consider the person as professional in the course of training. At this stage it is possible to speak about technology of training as to system of methods of training (a concrete, professional technique of teaching) or as about science about the general regularities of training (psycho-philosophical methods in training).

It is a system of standard impacts on the student: lectures and seminars (here not to replace a role of identity of professor with any technologies, it is enough to ask a question of the hidden knowledge or of nonverbal forms of transfer of knowledge which, in my stay by the student, were so skillfully owned by professor Lemleyn V. G. or professor Aronov R. A. training me., or (subsequently) academician of the Russian Academy of Sciences, professor Matrosov V. L. and other my teachers), standard tasks and calculations, laboratory and examinations, consultations, including computer and remote (here where a scope for technologies!) at the Ryazan radio engineering university (which the author represents).

As any technology, this concrete technology of training in a subject has the lower and top limits of applicability and difficulty of realization.

\section{Common thesis of theory}

It is possible to prove strictly, mathematically (entering the corresponding criteria and conducting mass examination and testing) that take place the following theses (are fair).

THESIS 1. Any technology of training in the teacherpupil system in principle is focused on averaging, mass replication.

THESIS 2. There are no "productions" technologies of outstanding experts in one of types of knowledge.

Orientation to "middling person", production of the expert of the average level of knowledge - here sense of all technologies of the higher school. Partially we can destroy (or to shift it "to the right") the top side of applicability technologists of training unless one improvisation, concrete approach to the specific student (but who will give so many hours at the higher school?). Thus, already at the first stage of communication "teacher-pupil" vapors the following thesis takes place.

THESIS 3. Any technology of training in the teacher pupil system internally (is not removable) is contradictory.

Technological approach to the second dialectic side of the teacher pupil system is represented absolutely unacceptable - it is education of the personality, decent person, patriot of the Fatherland. The last, by the way, is

\footnotetext{
Corresponding author: mironov.v.v@,rsreu.ru
} 
integral from category of "reciprocity" what mass departure of the Russian experts of the highest class out of borders of the Fatherland (visually testifies at full tranquility of the responsible officials assured, apparently, "... that we can own Platoones to and fast reasons Nevtones the Russian land to give rise").

Let's address authoritative opinions in these contradictory questions - to J.J. Rousseau, F.-M. Voltaire, L.N. Tolstoy, V.A. Sukhomlinsky. The link of their pedagogical systems - uniqueness, originality of the personality and, as a result, originality of pedagogical impact on it and, so unacceptability of technologies in general is central (the emperor Neron, either GenghisKhan, or I.V. Stalin could argue here in detail!).

At the same time there is an idea of the unified, technological impact on the personality which is going back to views and J. Locke's doctrines. In the Soviet period this idea gained development in A.S. Makarenko's works and was demanded by time.

This technological approach to the personality was one of the failure reasons in the solution of the fundamental problem of education of "the new person" proclaimed in the CPSU Program of 1961 and in its Modernization in 1986.

THESIS 4. There are no effective pedagogical technologies for education of the positive human person.

Proving this thesis, we will point, in particular, to that indisputable fact that one of education elements in the teacher pupil system is credibility. But the technology for the nature is anti-credibility.

Thus, there are no effective pedagogical technologies for education already because the thesis is fair.

THESIS 5. It is impossible to talk to masses confidentially.

The idea innovative is represented to even more disputable (the word, so well-loved by some officials that it should be beaten out gold letters on a pediment of their building - "The present generation of the Russian people will live under innovative capitalism!") pedagogical technologies. Really, such technologies can arise there and then where and when there is a new system of human values (as it was in 1917). However international and domestic experience shows that there is no such viable system today.

In such situation on advance of information technologies in the teacher pupil system, inevitably there are immemorial, Russian, "damned" questions. In attempt to answer them distinctly it is looked through tactical, political reasons, desire to replace difficult, financially capacious work as loud "scientific" phraseology.

At the same time, speaking about specific aspects of applicability at different stages of training of technologies in communication of the teacher and pupil, it is impossible "to splash out together with water and the child"! In other words, what general (inherent in training process on the whole) problems of communication of the teacher and pupil, what design features of technologies of early stages? Let's consider briefly these, not rhetorical, questions.

What to understand as pedagogical technology in the "teacher-pupil" system? The pedagogical technology is rather general system of components of pedagogical and educational activity in their certain temporary sequence directed to achievement of the objectives of training, education and the general development of the pupil.

What peculiar features of technologies perhaps also need to be introduced, in our opinion, in the teacher pupil system of the formed uniform educational space in present period?

These are, first of all:

- standardization of educational standards at their certain internal variability and alternativeness,

- complete approach, systemacity and dialectic interrelation separate component of system,

- a support on good breeding and democratization, on an education humanization,

- orientation to the individual, but not on mass "product",

- modern information and technological preparation of educational and pedagogical shots.

\section{Conclusions}

Building the most general reference points of pedagogical "technologies" in the "teacher-pupil" system it is necessary to provide in them various levels:

- conceptual,

- diagnostic,

- target,

- information and substantial,

- methodical,

- analytical,

- control,

- correcting.

Within these general recommendations under each student (or uniform group of students or, more generally, pupils) teachers will design concrete technologies of training. And then the result is not guaranteed!

Thus, the author, developing the researches begun in early years in work comes to conclusions that:

1) at early stages of training (adequate) computer or information technologies are useful, they allow to address all audience at once and to put a certain obligatory minimum which is well acquired by them at appropriate diligence in pupils;

2) at the highest stages of training, when training professionals it is necessary to leave from the general technologies and their standards and under each pupil or the student to develop individual "technology" of his training.

However, other views take place too to be $[3,4]$.

\section{References}

1.Modern dictionary of foreign words. (Russian word, Moscow, 1993)

2.V. V. Mironov, Pedagogical technologies at the higher school: whether absurdity? (Ryazan, 1995)

3.J. Hautamäki, Finnish Lessons What Can the World Learn from Educational Change in Finland? (TCP, New York, 2011)

4. R. Elmore, I Used to Think... And Now I Think. (ed.) (Harvard Education Press, Cambridge, 2011) 